Gut, 1987, 28, 675-680

\title{
Effect of long term lactulose ingestion on secondary bile salt metabolism in man: potential protective effect of lactulose in colonic carcinogenesis
}

\author{
G P 'AN BERGE HENEGOUWEN, S D J VAN DER WERF, \\ ANC A TH RUBEN \\ From the Department of Internal Medicine and Gastroenterology, Municipal Hospital, Wagnerlaan, Arnhem, \\ The Netherlands
}

SUMMARY This study investigated whether colonic absorption of secondary bile acids, especially deoxycholate in patients with adenomas could be decreased by oral lactulose. Bile acid metabolism was studied using bile sampling and ${ }^{14} \mathrm{C}$-deoxycholate kinetics in patients with colonic adenomatous polyps before and after four and 12 weeks of lactulose, $60 \mathrm{~g} /$ day. The results indicate that lactulose decreased the deoxycholate pool size from a mean of $22 \cdot 0$ (SD: $\pm 13 \cdot 8)$ to 14.3 $( \pm 7 \cdot 6) \mu \mathrm{mol} / \mathrm{kg}(\mathrm{p}<0.025)$. Deoxycholate absorption fell from $3.8( \pm 2 \cdot 3)$ to $2.9( \pm 1.4 \mu \mathrm{mol} / \mathrm{kg} / \mathrm{d}$ (ns). The biliary bile acid composition decreased significantly in deoxycholate after four and 12 weeks with a rise in primary bile acids. There was a highly significant correlation between the $\%$-change in DCA input and the \%-change in DCA pool size $(r=0 \cdot 89)$. Intestinal transit measured by the pellet method $(4 \cdot 1 \pm 1.9$ to $2 \cdot 4 \pm 0.6$ day; $\mathrm{p}<0 \cdot 01)$ and faecal $\mathrm{pH}$ decreased, while stool frequency and weight rose significantly. Significant correlations between the \%-change in gut transit time and the \%-change in DCA pool size or \%-change in DCA input were absent. The results show that it is possible to lower colonic secondary bile acid absorption by long term lactulose feeding. This effect can be mediated by accelerated transit and the acidification of the colonic contents.

Epidemiological findings suggest environmental influences play an important role in the development of large bowel cancer. ${ }^{1-3}$ Among other factors a low intake of dietary fibre has been considered significant. ${ }^{+}$The hypothesis that secondary bile acids may act as promotors of colonic carcinogenesis and that their formation may be enhanced by an alkaline $\mathrm{pH}$ due to a high fat, low dietary fibre diet, has received attention more recently. ${ }^{56}$

This concept is in agreement with early observations of high faecal bile salt concentrations in the presence of some species of anaerobic bacteria able to dehydrogenate the bile acid nucleus in high risk populations. ${ }^{7 \times}$ Slow gut transit time has been proposed as an additional promoting factor, but this

Address for correspondence: G P van Berge Henegouwen. Municipal Hospital, Wagnerlatan 55, 6815 AD Arnhem. The Netherlands.

Received for publication 10 October 1986. remains controversial. ${ }^{911}$ Further supporting evidence in favour of a promoting role of secondary bile acids has been produced: faecal $7 \alpha$-dehydroxylation, the initial step in bile acid nucleus conversion, and the ratio of faecal anaerobic to aerobic bacteria proved to be increased in patients with colonic adenomas. ${ }^{11-1.3}$ A tumour promoting effect and mutagenicity of secondary bile acids has been shown. ${ }^{1+16}$ In our studies using colonic deoxycholate (DCA) absorption as an in vivo marker of mucosal exposure to secondary bile acids in man, we found a higher DCA-absorption and a more anaerobic gut flora in patients with colonic adenomas at high risk of colon cancer as compared with matched subjects. ${ }^{17}{ }^{18}$ Stimulation of cell proliferation by secondary bile acids (lithocholic and deoxycholic acid) in the colon can be shown..$^{19-21}$

Alterations of secondary bile acid metabolism in 
patients at high risk for colon cancer have not been explored, because the data reported are confined to changes in primary bile acid pool sizes and biliary bile acid composition. In view of the intimate relationship of colonic exposure to secondary bile salts, the colonic microenvironment $(\mathrm{pH}$, flora) and gut transit, it is important to evaluate such changes induced by oral feeding of fermentable non-absorbable carbohydrates such as lactulose, causing acidification and dilution of colonic contents, ${ }^{22}$ in patients at high risk for colon cancer. Lactulose is metabolised to organic acids by the colonic flora and reduces the $\mathrm{pH}$ in the right colon to less than $5 \cdot 0,{ }^{22}$ whereas in in vitro experiments the $7 \alpha$-dehydroxylation of bile acids is inhibited below $\mathrm{pH} 6 \cdot 0-6 \cdot 4$. $^{2.25}$

It could therefore be predicted that lactulose will reduce the $7 \alpha$-dehydroxylation of bile acids and evidence for this has been presented by Thornton and Heaton, ${ }^{26}$ who showed that oral feeding of lactulose could reduce biliary DCA. The protocol of the present study was designed to find out whether pool size and absorption of the secondary bile salt DCA, a risk factor for development of colon cancer, ${ }^{17}$ could be reduced by lactulose.

\section{Methods}

PATIENTS

Eight female patients (mean age 57.4 years; $\mathrm{SD} \pm 12 \cdot 2$ ) with histologically diagnosed colonic adenomatous polyps were investigated. All patients were within $10 \%$ of ideal body weight. In all the risk of colon cancer was increased because the removed polyps showed dysplasia, the size was more than $2 \mathrm{~cm}$ in diameter, or more than two adenomas per patient were present. None of the patients was taking any medication or was aware of any other illness. Ultrasound showed no abnormality of liver and gall bladder.

Food intake in the week before the studies was assessed so that individual consumption was known. Subjects were asked to maintain their eating habits unchanged during the 12 weeks of the study. Informed consent was obtained from each patient and approval for the study was obtained from the Ethical Committee on Medical Research in the Municipal Hospital at Arnhem.

\section{EXPERIMENTAL PROCEDURE}

The patients were studied before, after four weeks, and after 12 weeks of oral lactulose feeding. Lactulose treatment was given in three doses of $20 \mathrm{~g}$ per day as lactulose syrup, containing $670 \mathrm{~g}$ lactulose per litre (Duphalac ${ }^{\circledR}$, Duphar, Amsterdam, The Netherlands). During the first week three times $15 \mathrm{ml}$ was given with meals; then each dose was increased to $30 \mathrm{ml}$, giving a daily dose of $60 \mathrm{~g}$ lactulose for a period of 12 weeks. It was the aim to obtain one to two soft stools per day. Two patients developed diarrhoea and the dose had to be reduced to $30 \mathrm{~g}$ per day. Duodenal bile samples after cholecystokinin (CCK; Kabi Vitrum, Stockholm, Sweden) stimulation for the analysis of biliary bile acids were obtained before, after four, and after 12 weeks of lactulose treatment.

Bile acid kinetic studies for measuring deoxycholate pool size, turnover rate and input rate and intestinal transit and faecal $\mathrm{pH}$ were measured before and after 12 weeks of lactulose treatment.

\section{BILE ANALYSES}

To study deoxycholate kinetics $10 \mu \mathrm{Ci}\left(24-{ }^{1+} \mathrm{C}\right)$ sodium deoxycholate (Radiochemical Centre, Amersham, England) was injected iv. On the next four mornings less than $2 \mathrm{ml}$ fasting duodenal bile was collected after gall bladder stimulation with CCK. Of each bile sample $1 \mathrm{ml}$ was taken and diluted with isopropanol (1:9) immediately after sampling. All samples were stored at $-20^{\circ} \mathrm{C}$. Bile acid analyses and deoxycholate kinetics were done as described previously with the isotope dilution technique..$^{27} 2 \mathrm{x}$

We calculated the input into the bile acid pool of newly formed DCA from the colon (which is colonic synthesis minus loss of newly synthesised material in the faeces) as the pool size of DCA multiplied by its fractional turnover rate (FTR). The FTR is the fraction of the DCA pool that is replaced daily by newly synthesised material.

INTESTINAL TRANSIT AND FAECAL $\mathrm{pH}$

Gut transit time and faecal $\mathrm{pH}$ were measured before and after 12 weeks of lactulose treatment. Gut transit time was defined as the period between ingestion and excretion of $80 \%$ of 25 pellets ingested on the morning of day 1 , day 2 , and day 3 of the study. On each consecutive day a different kind of pellet was given and all stools were kept frozen on dry ice the next five days. After radiography of the faecal bags the mean transit time of the three markers was calculated. This is a modification of the method described by Cummings et al. ${ }^{24}$ Stool weights and stool frequency were recorded daily and the $\mathrm{pH}$ was measured immediately after defecation. Faecal $\mathrm{pH}$ was measured after saline dilution (v/v:1/1) using a pH electrode (Radiometer Copenhagen). Of each defecation three samples were analysed and reproducibility of faecal $\mathrm{pH}$ measurements yielded good results within stool samples.

\section{STATISTICAL ANALYSES}

The statistical significance of the results was calculated using the Student's $t$ test for paired values. 

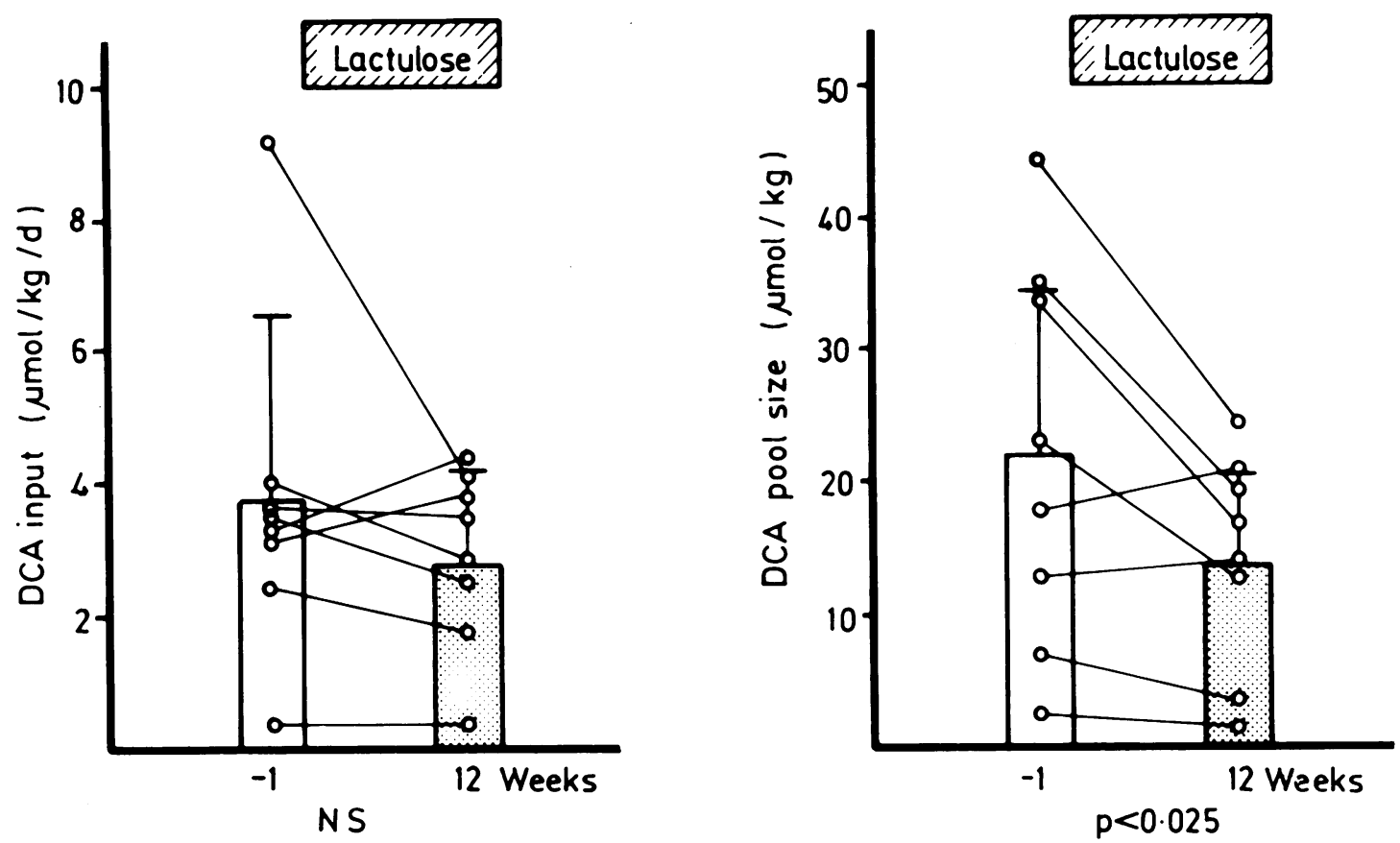

Fig. 1 In the left panel colonic deoxycholate input (individual and mean values $\pm S D$ ) is shown before and after 12 weeks of lactulose feeding. In the right panel deoxycholate pool size is shown before and after 12 weeks of lactulose in eight subjects with colonic adenomas.

Correlation coefficients were calculated according to the method of least squares with Spearman's rank correlation test.

\section{Results}

EFFECTS ON GUT TRANSIT TIME, FAECAL PH, FAECAL WEIGHT AND STOOL FREQUENCY Measurements of gut transit time before and after 12 weeks of lactulose showed a significant reduction of $4 \cdot 1( \pm 1 \cdot 9)($ mean \pm SD) to $2 \cdot 4( \pm 0.6)$ day $(\mathrm{p}<0.01)$. Faecal $\mathrm{pH}$ was slightly but significantly decreased in our subjects $(\mathrm{p}<0 \cdot 01)$. The mean $\mathrm{pH}$ decreased from $7 \cdot 3( \pm 0 \cdot 6 ; \mathrm{SD})$ pretreatment to $6 \cdot 8( \pm 0 \cdot 5)$ after 12 weeks of lactulose. Stool frequency increased from $1.3( \pm 0.4)($ mean \pm SD) to $2.0( \pm 0.6)$ bowel movements per day $(\mathrm{p}<0.01)$. Wet faecal weight increased from $156( \pm 69)$ to $232( \pm 98)$ g per day $(\mathrm{p}<0 \cdot 01)$.

\section{EFFECT OF LACTULOSE ON DEOXYCHOLATE} METABOLISM

Deoxycholate pool size decreased significantly from $22.0( \pm \mathrm{SD} 13.8) \mu \mathrm{mol} / \mathrm{kg}$ to $14.3( \pm 7.6)$ after 12 weeks $(p<0 \cdot 025)$. In two patients the pool size was not decreased. One patient had a very low DCA pool size (Fig. 1). In three of the eight patients no reduc- tion in colonic DCA input was observed. Although in three others a reduction was observed, the total result did not show a significant difference between pretreatment and 12 weeks of lactulose treatment (Fig.1).

The mean value for DCA input was $3.8( \pm 2.3)$ $\mu \mathrm{mol} / \mathrm{kg} / \mathrm{d}$ before and $2.9( \pm 1.4) \mu \mathrm{mol} / \mathrm{kg} / \mathrm{d}$ after lactulose treatment. Fractional turnover rate of DCA was unchanged. The mean $( \pm S D)$ pretreatment level was $0.217( \pm 0.114) / \mathrm{d}$ and the mean FTR after lactulose was $0.233( \pm 0 \cdot 106) / \mathrm{d}$. This trend in reduction of DCA input did correlate well with the shrinkage DCA of pool size during lactulose treatment.

The correlation between $\triangle \%$ DCA input or colonic absorption and $\triangle \%$ DCA pool size was highly significant $(n=8 ; r=0.89 ; p<0.01)$, as would be expected. No significant correlation was detected between the change in gut transit time $(\triangle \%)$ and $\triangle \%$ DCA pool size $(r=0 \cdot 21)$ and $\triangle \%$ DCA input $(r=-0 \cdot 17)$, if pretreatment values were compared with those after 12 weeks of lactulose feeding.

BILIARY BILE ACID COMPOSITION

For the secondary bile acid DCA biliary bile acid composition showed a similar type of reduction after lactulose treatment as observed for DCA pool size 


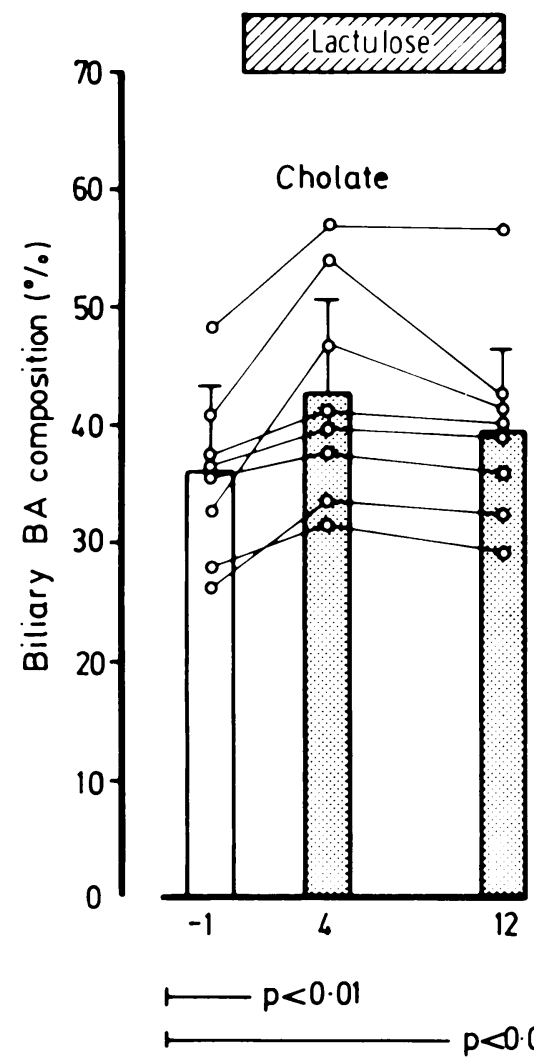

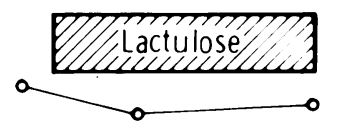

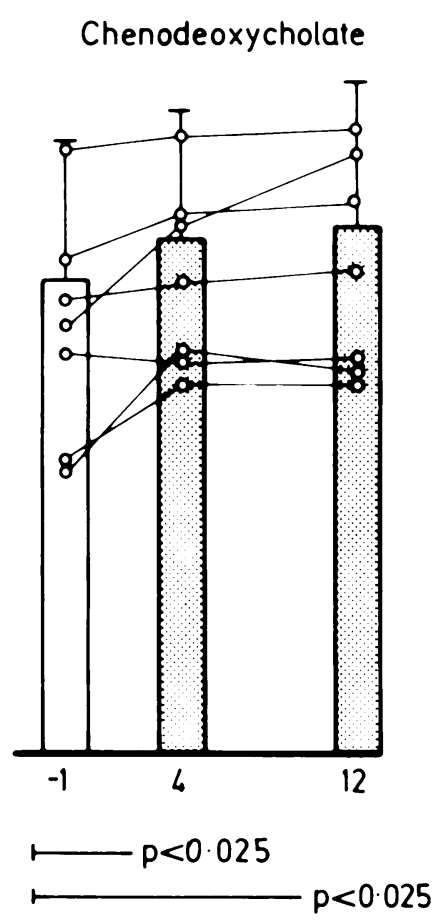

Fig. 2 Individual and mean values ( $\pm S D$ ) of biliary bile acid composition (\%) before, after four and after 12 weeks of lactulose feeding in eight subjects with colonic adenomatous polyps are shown.

(Fig. 2). The mean biliary DCA composition showed a reduction from pretreatment levels of $22 \cdot 0 \pm 13 \cdot 8$ (mean $\% \pm \mathrm{SD}$ ) to $13 \cdot 5 \pm 11.9 \%$ after four weeks and $15 \cdot 0 \pm 11 \cdot 5$ after 12 weeks of lactulose feeding (Fig. 2). The other secondary bile acid, lithocholic acid (LCA) did not change significantly. The mean pretreatment LCA proportion was $2.5 \%( \pm 1 \cdot 0)$; This proportion was $2 \cdot 8 \%( \pm 1 \cdot 0)$ after four weeks and $2 \cdot 8 \%( \pm 0 \cdot 8)$ after 12 weeks of lactulose feeding.

In association with the reduction of DCA in biliary bile acid composition, a significant rise of the primary bile acids cholate (CA) and chenodeoxycholate (CDCA) was observed.

The mean CA $( \pm S D)$ increased from the pretreatment level of $35.9 \%( \pm 6.8)$ to $42.6 \%( \pm 8.7)$ after four weeks and to $39.5 \%( \pm 7.7)$ after 12 weeks lactulose treatment (Fig. 2).

Chenodeoxycholate increased from pretreatment levels of $40.0 \%( \pm 13.8)$ to $43.7 \%( \pm 10.9)$ after four weeks and $44 \cdot 5 \%( \pm 11 \cdot 7)$ after 12 weeks (Fig. 2 ). Both changes in $\mathrm{mol} \%$ of $\mathrm{CA}$ and CDCA were statistically significant at four and 12 weeks in comparison with pretreatment levels.

The trend to a reduction of gut transit time during lactulose did not correlate well with the change in biliary DCA. The correlation between $\triangle \%$ DCA in bile and $\triangle \%$ gut transit time was not significant $(r=0 \cdot 34)$.

\section{Discussion}

In this study a significant reduction in secondary DCA pool size was obtained by oral feeding of lactulose, a synthetic, non-absorbable disaccharide. A significant reduction in DCA input was not obtained, but this may be because of the small number of subjects studied. The change in DCA input, however, did correlate well with the change in DCA pool size. A reduction in the proportion of biliary DCA in contrast with an increase in the proportion of CA and CDCA after lactulose has previously been described by Thornton and Heaton ${ }^{26}$ 
who fed lactulose in similar doses, but only for six weeks, to healthy women preferably with highly supersaturated bile.

Although total pool size was not measured, one could assess individual bile acid pool sizes from the DCA pool size and biliary bile acid composition. As the proportion of CA and CDCA in bile did increase significantly during lactulose at the expense of DCA, similar changes can be expected in individual bile acid 1 ol sizes.

Altl ung reduction in DCA pool size could be becaus of the established accelerated colonic transit, where the time available for the formation or absorption of DCA is reduced, no significant correlation was found between the change in gut transit time and the change in DCA pool size or DCA $\mathrm{mol} \%$ in bile or DCA input. Previously we have seen that the input of DCA varied significantly with gut transit in young people but not in older subjects. ${ }^{2 \times}$ Marcus and Heaton $^{\text {31 }}$ on the other hand were able to expand or reduce DCA pool size in a larger group of normal subjects by treating them with respectively loperamide and senna laxative. They were also able to show a significant positive correlation between the change in DCA pool size and the change in gut transit time. On the other hand acidification of the colon below $\mathrm{pH} 6 \cdot()$ over at least 12 hours per day could also reduce DCA formation considerably. Furthermore the availability of free DCA for colonic absorption will be reduced due to precipitation and absorption to solid matter at a lower $\mathrm{pH}$ in the right colon.

The lack of an appreciable effect of lactulose on the proportion of biliary lithocholate could be caused by the very low degree of luminal solubility of this bile acid, even at the normal $\mathrm{pH}$ level of the colon.

If we assume that a more alkaline $\mathrm{pH}$ in colonic microenvironment can augment the risk of colonic cancer $^{31}$ then long term treatment with non-absorbable disaccharides capable of acidifying colonic contents could have potential for the prevention of colonic cancer. It is possible to study patients with adenomas after polypectomy to find out if the addition of lactulose or other fermentable carbohydrates to the diet can prevent a recurrence of adenomatous polyps. Lactulose seems a suitable compound to be examined. Its laxative effect caused by acidification of colonic contents in patients with portosystemic encephalopathy has been well documented. ${ }^{32-34}$ Patient compliance can be easily monitored by breath hydrogen excretion or faecal $\mathrm{pH}$ measurements. Its long term effects on secondary bile acid metabolism can now be monitored using 24${ }^{13} \mathrm{C}$-deoxycholic acid kinetics as recently described. ${ }^{35}$

One disadvantage in the chronic use of lactulose could be the described adaption phenomenon. ${ }^{36} \mathrm{~A}$ chronic load of a non-absorbable sugar can induce an increase in number or in activity of lactic acid metabolising bacteria, resulting in a better efficiency of the colonic flora to digest the non-absorbable carbohydrate. On the other hand caecal fluid $\mathrm{pH}$ fell more quickly after a chronic load of lactulose than after an initial load. Also colonic hydrogen production did increase after a chronic load of lactulose. ${ }^{36}$

In our study the effect of lactulose on biliary bile acid composition, although more pronounced after four weeks, was sustained up to 12 weeks of lactulose feeding.

In conclusion secondary bile acid metabolism can be modified by long term lactulose ingestion, reducing colonic exposure to DCA. Both colonic intraluminal acidification and faster gut transit could be responsible for this effect. The results justify further studies on the potential protective effect of lactulose or other non-absorbable fermentable carbohydrates on the recurrence rate of colonic polyps.

We are grateful to Dr J K Kutsch Lojenga, hospital pharmacist and Dr D Palsma, head of the Department of Nuclear Medicine for excellent technical assistance and to Mrs Ineke Janssen-Volman for expert secretarial assistance.

\section{References}

1 Doll R, Payne H, Waterhouse J. Cancer incidence in five continents. Berlin, New York: Technical Report Union against Cancer, 1966.

2 Wynder EL, Shigematsu T. Environmental factors in cancer of the colon and the rectum. Cancer 1967; 20: $1520-61$.

3 Correa P, Haenszel W. Epidemiology of large bowel cancer. Adv Cancer Res 1978; 26: 1-141.

4 Burkitt DP. Epidemiology of cancer of the colon and rectum. Cancer 1971; 28: 3-13.

5 Thornton JR. High colonic $\mathrm{Ph}$ promotes colorectal cancer. Lancet 1981; i: 1081-3.

6 Burkitt DP. Colorectal cancer: prevention, epidemiology and screening. In: Winaver SJ, ed. Progress in cancer research and therapy. New York: Raven Press, 1981: 15-6.

7 Hill MJ. The etiology of colon cancer. CRC Crit Rev Toxicol 1975; 4: 31-82.

8 Cook JM, Kennaway EL, Kennaway NM. Production of tumours in mice by deoxycholic acid. Nature 1940; 145: 627-8.

9 Burkitt DP, Walker ARP, Painter NS. Effect of dietary fibre on stools and transit time and its role in causation of disease. Lancet 1972; ii: 1408-11.

10) Glober GA, Moore JO, Kline KL. Bowel transit in two populations experiencing similar colon cancer risks. Lancet 1974; ii: 80-2.

11 Finegold SM, Flora DJ, Atteberry HR. Faecal bacteriology of colonic polyp patients and control patients. Cancer Res 1975; 35: 3407-17.

12 Moore WEC, Holdeman LV. Discussion of current bacteriological investigation of the relationship between 
intestinal flora, diet and colon. Cancer 1975; 35: $3418-20$.

13 Mastromarini AJ, Reddy BS, Wynder EL. Profiles of anacrobic microflora of large bowel cancer patients and patients with non-hereditary large bowel polyps. Cancer Res 1978; 38: 4458-62.

14 Narisawa T, Magadia NE, Wynder EL. Promoting effects of bile acids on colonic carcinogenesis after intrarectal instillation of $\mathrm{N}$-methyl-N-nitroso- $\mathrm{N}$ nitroguanidine in rats. $J$ Natl Cancer Inst 1974; 53: 1093-7.

15 Silverman SJ, Andrews AW. Bile acids: comutagenic activity in the Salmonella-mammalian-microsome mutagenity test. J Nall Cancer Inst 1977; 59: 1557-9.

16 Summerton J, Goeting N, Trotter GA, Taylor I. Effect of deoxycholic acid on tumour incidence distribution and receptor status of colorectal cancer in the rat model. Digestion 1985; 31: 77-81.

17 Van der Werf SDJ, Nagengast FM, Van Berge Henegouwen GP, Huybregts AWM, Van Tongeren JHM. Colonic absorption of secondary bile acids in patients with adenomatous polyps and in matched controls. Lancet 1982; i: 759-62.

18 Van der Werf SDJ, Nagengast FM, Van Berge Henegouwen GP, Huybregts AWM, Van Tongeren JHM. Intracolonic environment and the presence of colonic adenomas in man. Gut 1983; 24: 876-81.

19 Fry RJM, Staffeldt E. Effect of a diet containing sodium deoxycholate on the intestinal mucosa of the mouse. Nature 1964; 203: 1396-8.

20 Weser E, Hella R, Tawli T. Stimulation of mucosal growth in the rat ileum by bile and pancreatic secretions after jejunal resection. Gastroenterology 1977; 73: 524-9.

21 Deschner EE, Raicht RF, The influence of bile on kinetic behaviour of colonic epithelial cells of the rat. Gastroenterology 1979; 76: 1120.

22 Bown RL, Gibson JA, Sladen GE, Hicks B, Dawson AM. Effects of lactulose and other laxatives on ileal and colonic $\mathrm{pH}$ as measured by a radiotelemetry device. Gut 1974; 15: 999-1004.

23 Midtvedt T, Norman A. Parameters in $7 \alpha$-dehydroxylation of bile acids by anaerobic lactobacilli. Acta Pathol Microbiol Scand 1968; 72: 313-29.

24 Aries V, Hill MJ. Degradation of steroids by intestinal bacteria. Biochim Biophys Acta 1970); 202: 535-43.
25 MacDonald IA, Singh G, Mahoney DE, Meier GE. Effect of $\mathrm{pH}$ on bile salt degradation by mixed fecal cultures. Steroids 1978; 32: 245-56.

26 Thornton JR. Heaton KW. Do colonic bacteria contribute to cholesterol gallstone formation? Effects of lactulose on bile. Br Med J 1981; i: 282, 1018-20.

27 Huybregts AWM, Schaik A van, Berge Henegouwen GP van, Werf SDJ van der. Serum lipids, biliary lipid composition and bile acid metabolism in vegetarian as compared to normal controls. Eur J Clin Invest 1980; 10: 443-9.

28 Van der Werf SDJ, Huybregts AWM, Lamers HLM, Van Berge Henegouwen GP, Van Tongeren JHM. Age dependent differences in human bile acid metabolism and $7 \alpha$-dehydroxylation. Eur J Clin Invest 1981; 11: 425-31.

29 Cummings JH. Jenkins DJA, Wiggins HS. Measurement of the mean transit time of dietary residue through the human gut. Gut 1976; 17:210-8.

30 Marcus SN, Heaton KW. Intestinal transit, deoxycholic acid and the cholesterol saturation of bile - three interrelated factors. Gut 1986; 27: 550-8.

31 Samelson SL, Nelson RL, Nyhuis LM. Protective role of fecal $\mathrm{pH}$ in experimental colon carcinogenesis. $J R$ Soc Med 1985; 78: 230-3.

32 Bircher J, Müller J, Guggenheim P, Haemmerli UP. Treatment of chronic portal systemic encephalopathy with lactulose. Lancet 1966; i: 890-2.

33 Bircher J, Haemmerli UP, Trabert E, Largiacher F, Mocetti T. The mechanism of action of lactulose in portal-systemic encephalopathy. Rev Fr Et Clin Biol 1971; 16: 352-7.

34 Orlandi F, Freddara U, Camdelaressi MT, et al. Comparison between neomycin and lactulose in 173 patients with hepatic encephalopathy. Dig Dis Sci 1981; 26: $498-506$

35 Stellaard F, Van Berge Henegouwen GP, Van der Werf SDJ, Berr F, Paumgartner G. Measurements of deoxycholic acid kinetics by stable isotope dilution technique and serum sampling. In: Paumgartner G, et al., eds. Enterohepatic circulation of bile acids and sterol metabolism. Lancaster: MTP, 1985: 263-6.

36 Florent C, Flourie B, Lebland A, Rautureau M, Bernier $\mathrm{JJ}$, Rambaud JC. Influence of chronic lactulose ingestion on the colonic metabolism of lactulose in man. J Clin Invest 1985; 75: 608-13. 